\title{
CORRECTION
}

\section{Correction to: Rheological characterization of potassium carbonate deep eutectic solvent (DES) based drilling mud}

Muhammad Hammad Rasool ${ }^{1} \cdot$ Asif Zamir $^{1,2} \cdot$ Khaled A. Elraies $^{1} \cdot$ Maqsood Ahmad $^{1} \cdot$ Muhammad Ayoub $^{3}$. Muhammad Adeem Abbas ${ }^{1} \cdot$ Imtiaz Ali $^{1}$

Published online: 13 January 2022

(c) The Author(s) 2022

\section{Correction to:}

Journal of Petroleum Exploration and Production Technology

https://doi.org/10.1007/s13202-021-01328-6

Wrong Figure 3:

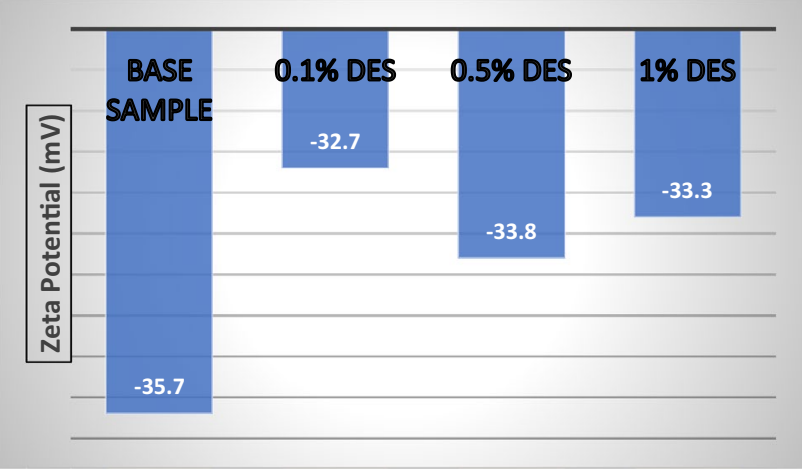

Correct Figure 3:

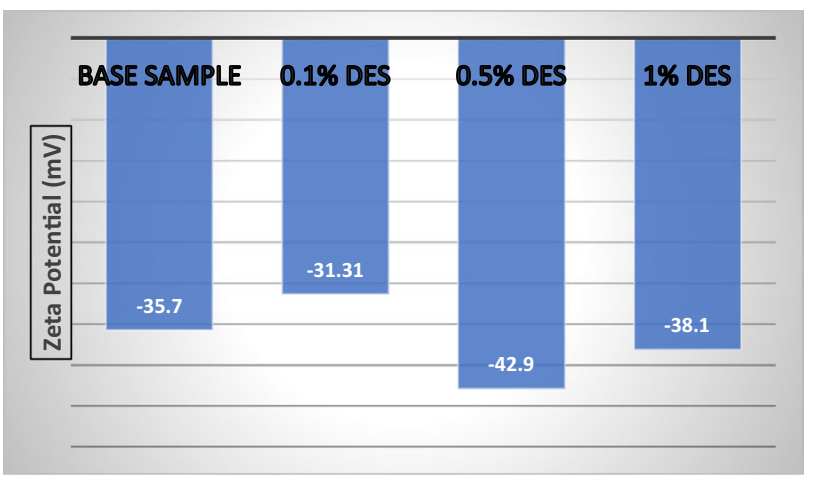

The original article can be found online at https://doi.org/10.1007/ s13202-021-01328-6.

Asif Zamir

asif.zamir@utp.edu.my

1 Petroleum Engineering Department, Universiti Teknologi PETRONAS, Bandar Seri Iskandar, Perak, Malaysia

2 Well Engineering Department, International College of Engineering and Management, Muscat, Oman

3 Chemical Engineering Department, Universiti Teknologi PETRONAS, Bandar Seri Iskandar, Perak, Malaysia 
Wrong Fig 4:

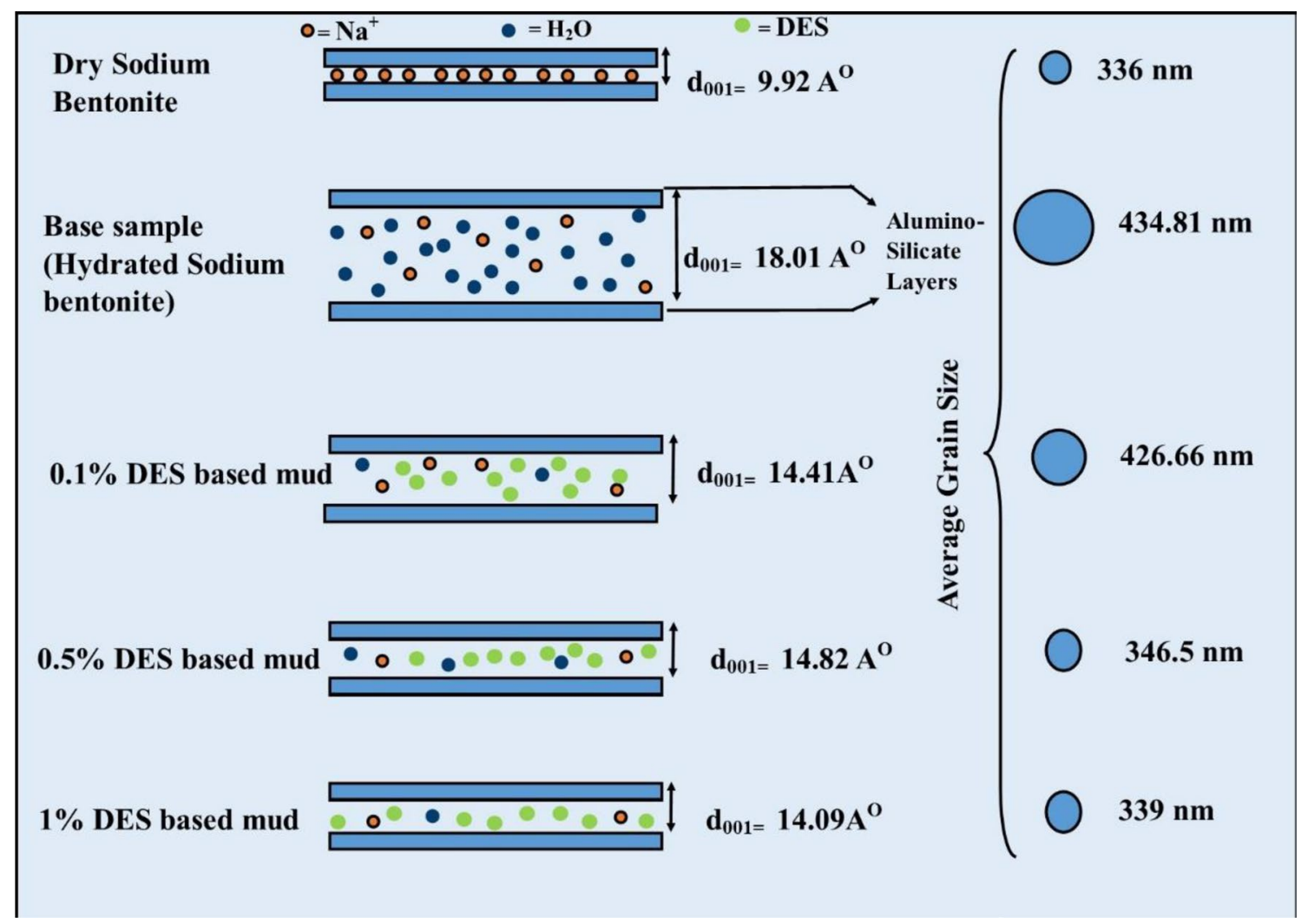


Correct Figure 4:

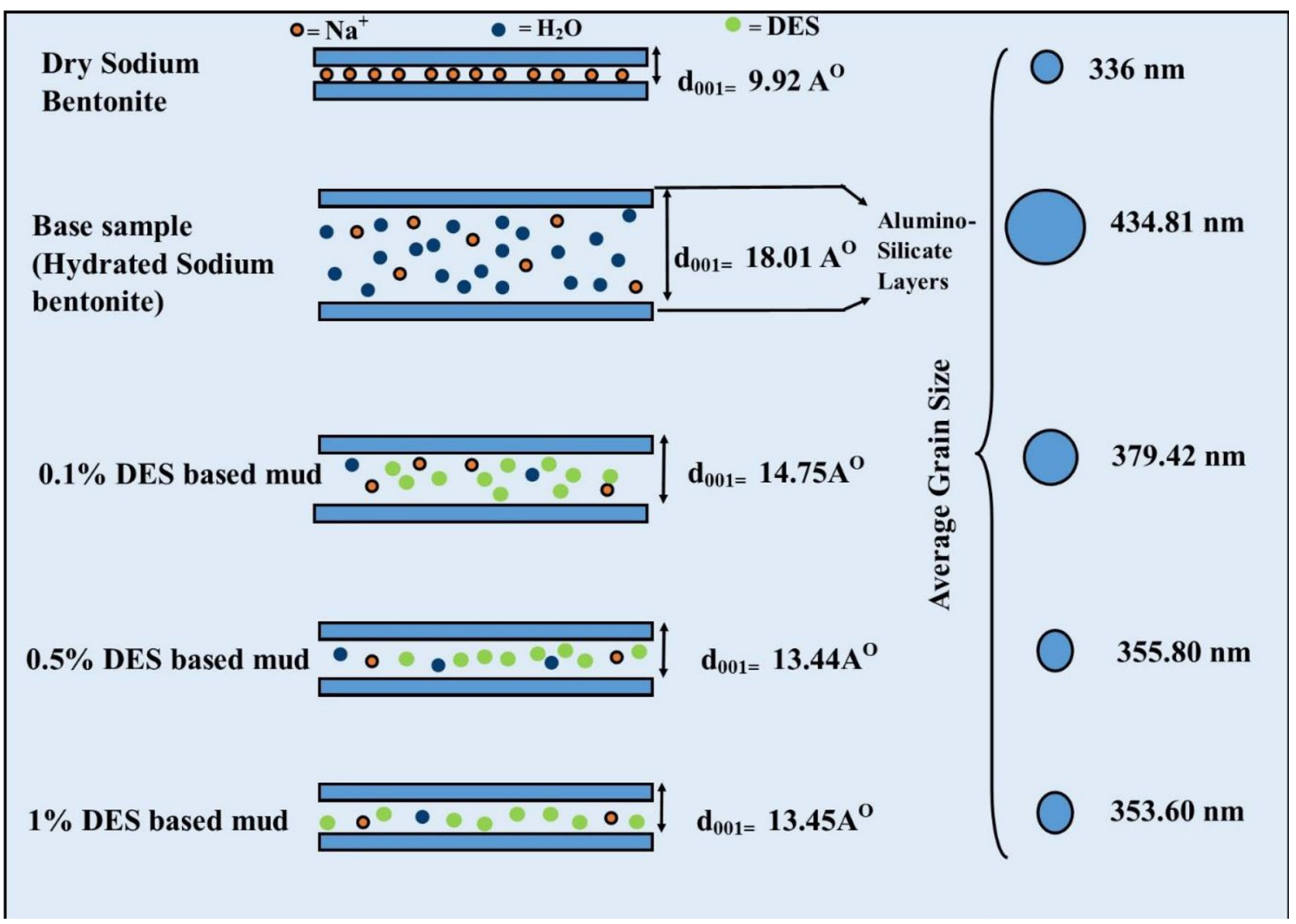

Incomplete Table 2:

\begin{tabular}{ll}
\hline Conc. & $\begin{array}{l}\text { Average grain size of } \\
\text { PC:Gly-based mud } \\
(\mathrm{nm})\end{array}$ \\
\hline Dry Na-Bt & 336 \\
Base sample & 434.81 \\
$0.1 \%$ & 379.42 \\
$0.5 \%$ & 355.80 \\
$1 \%$ & \\
\hline
\end{tabular}

Complete Table 2:

\begin{tabular}{ll}
\hline Conc. & $\begin{array}{l}\text { Average grain size of } \\
\text { PC:Gly-based mud } \\
(\mathrm{nm})\end{array}$ \\
\hline Dry Na-Bt & 336 \\
Base sample & 434.81 \\
$0.1 \%$ & 379.42 \\
$0.5 \%$ & 355.80 \\
$1 \%$ & 353.63 \\
\hline
\end{tabular}

Open Access This article is licensed under a Creative Commons Attribution 4.0 International License, which permits use, sharing, adaptation, distribution and reproduction in any medium or format, as long as you give appropriate credit to the original author(s) and the source, provide a link to the Creative Commons licence, and indicate if changes were made. The images or other third party material in this article are included in the article's Creative Commons licence, unless indicated otherwise in a credit line to the material. If material is not included in the article's Creative Commons licence and your intended use is not permitted by statutory regulation or exceeds the permitted use, you will need to obtain permission directly from the copyright holder. To view a copy of this licence, visit http://creativecommons.org/licenses/by/4.0/.

Publisher's Note Springer Nature remains neutral with regard to jurisdictional claims in published maps and institutional affiliations. 